\title{
The Use of Higher than the Normal Field-forcing Ratio of Synchronous Machines from Energy Storage Systems to Increase the Reliability of Power Supply to Consumers in Centralized and Decentralized Zones
}

\author{
Kamil Bakhteev ${ }^{1}$, Alexander Fedotov ${ }^{1}$, and Rinat Misbakhov ${ }^{1}$ \\ ${ }^{1}$ Kazan State Power Engineering University, Engineering center, 420066 Krasnoselskaya 51, Russia
}

\begin{abstract}
The paper presents the results of scientific research, firstly, the effectiveness of the use of energy storage systems as stabilizers of alternating current frequency as a part of gas piston installations in decentralized and centralized (operating in parallel with the power system) and their simultaneous use for excitation forcing of generators during voltage dips is proved, secondly, The efficiency of using increased field-forcing ratio of the synchronous generator of the gas piston installations is proved to improve the power quality of industrial consumers.
\end{abstract}

\section{Introduce}

The operation of low-voltage electric motors for oil pump drives, fans, and similar mechanisms included in technological protections of technological processes, microprocessor technology, telecommunications systems, automated process control systems, expensive medical equipment, standard blocks of new digital technologies and the Internet, is often interrupted by short durations (in milliseconds) power failures and overloads that occur 20-30 times a year and lead to expensive economic damage [1-3].

The existing market for solutions to improve the power quality is focused on the old system of views and design standards for protecting enterprises from 2-3 power outages per year, although up to $10-40$ occur in different regions $[4,5]$. Thus, according to the data of the enterprise Organic Synthesis PJSC, about 15 shortterm voltage dips (VD) per year lead to disruptions in continuous technological processes, which causes the damage of about one hundred eighty-eight thousand euros. for one short-term power outages (STPO) $[6,7]$. These numbers show that technical solutions that are very expensive to compensate for the effects of STPO can be quite economically justified $[8,9]$.

One of the effective ways to improve the reliability and power quality during STPO in the areas of a centralized and decentralized power supply is the use of gas piston installations (GPI) running on natural or associated gas. In decentralized zones of power supply, they must be supplemented by energy storage systems (ESS) in the presence of sharp disturbances from the load side.

In this paper, we consider the technical aspects of the use of ESS, including the excitation forcing of synchronous generators GPI in order to increase the level of residual voltage on the load during short circuits in the supply grid $[10,11]$. It also considers the use of ESS in centralized power supply systems to ensure the excitation forcing of synchronous electric motor (SEM) and generators (SG), connected to internal industrial power supply systems.

The main problem of using the excitation forcing of synchronous machines (SM) at the moment STPO is that VD extends to the entire power supply system. As a result, the valve converters of the SM excitation systems are powered by a low voltage and cannot provide the needed magnification of the field-forcing ratio.

In the paper, as the simplest indicator for evaluating the efficiency of excitation forcing, the concept of "allowable voltage level under stability conditions" is used on the common buses from which the electric drives are powered.

\section{Simulating model of work of an autonomous gas-piston installation, including a synchronous generator and energy storage systems}

GPI from gas turbine and diesel generator sets are distinguished by simplicity, reliability of the design and the highest electrical efficiency, which when working on Russian natural gas is approximately $41-44 \%[12,13]$. The widespread use of GPI is currently limited by their sensitivity to significant rise and shedding load, which leads to the output of frequency values beyond the standard values and to the corresponding operation of emergency automatics. 
The solution of the problems described and a general increase in the efficiency of closed energy systems is possible through the joint use of GPI with ESS, which allows the GPI to be put in the basic mode of operation with a constant load. Changes in the load are worked out with ESS. Studies of the effectiveness of the action of ESS under disturbances from the load side were carried out on the example of a typical scheme of small generation, Figure 1.

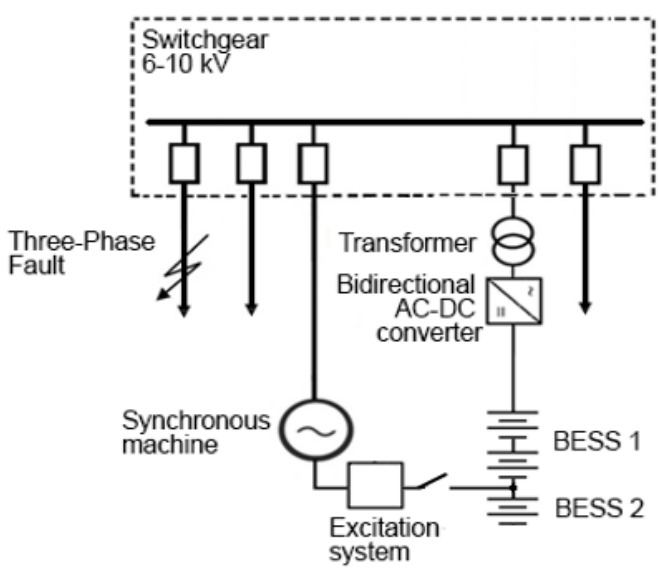

Fig. 1. Schematic diagram of connecting ESS and SG working autonomously.

An appropriate simulation model was developed in the Matlab-Simulink software environment [14], which is shown in Figure 2, where ESS presented simplified in the form of controlled AC sources.

The combination of ESS with an autonomous generator involves solving a number of issues related to the selection and optimization of the parameters of the created electrotechnical complex. The simulation results without the use of ESS are presented in Figure 3.
As can be seen from Figure 3, at times corresponding to the connection of an additional load $(5 \mathrm{~s}, 11 \mathrm{~s}, 16 \mathrm{~s})$, the voltage frequency decreases to values of $48.5 \mathrm{~Hz}$, $46.0 \mathrm{~Hz}$, and $43.8 \mathrm{~Hz}$, respectively.

At the moments of disconnection of the additional load $(8 \mathrm{~s}, 13 \mathrm{~s}, 19 \mathrm{~s})$, an increase in the frequency of the voltage above the nominal value is observed to $51.7 \mathrm{~Hz}$, $53.3 \mathrm{~Hz}$, and $54.2 \mathrm{~Hz}$, respectively. Technological emergency automatics will disconnect the load even when the frequency changes beyond $50 \pm 1.5 \mathrm{~Hz}$. The use of ESS solves the problem of the sensitivity of the GPI to a stepwise rise/shedding load, as can be seen from Figure 4.

Figure 4 shows graphs of changes in the main electrical parameters of the simulated circuit in the case of using a ESS (simulated by a controlled current source) to compensate for the rise and shedding load. In graph 4, Figure 4 shows the change in current from the side of the current source, on which you can see a linear decrease in the compensation current from the maximum value equal to the magnitude of the rise (or shedding) load current to 0 for a given time interval of $1 \mathrm{~s}$. As can be seen from the graph of the frequency variation of the generator voltage (graph 1, Figure 4), this compensation algorithm allows you to almost completely smooth out the frequency deviation from the nominal value.

The nominal power of the ESS must be selected based on the power of the greatest dynamic load, taking into account the margin for power entering the exciter $\mathrm{SG}$ in the excitation forcing mode, Figure 1. In this example, Figure 4, for SG with a power of $1000 \mathrm{~kW}$ in nominal mode, the excitation power is $40 \mathrm{~kW}$. In the mode of two-time excitation forcing - $80 \mathrm{~kW}$. Given the maximum load rise of $350 \mathrm{~kW}$, the ESS should be selected for a power of $450-500 \mathrm{kVA}$.

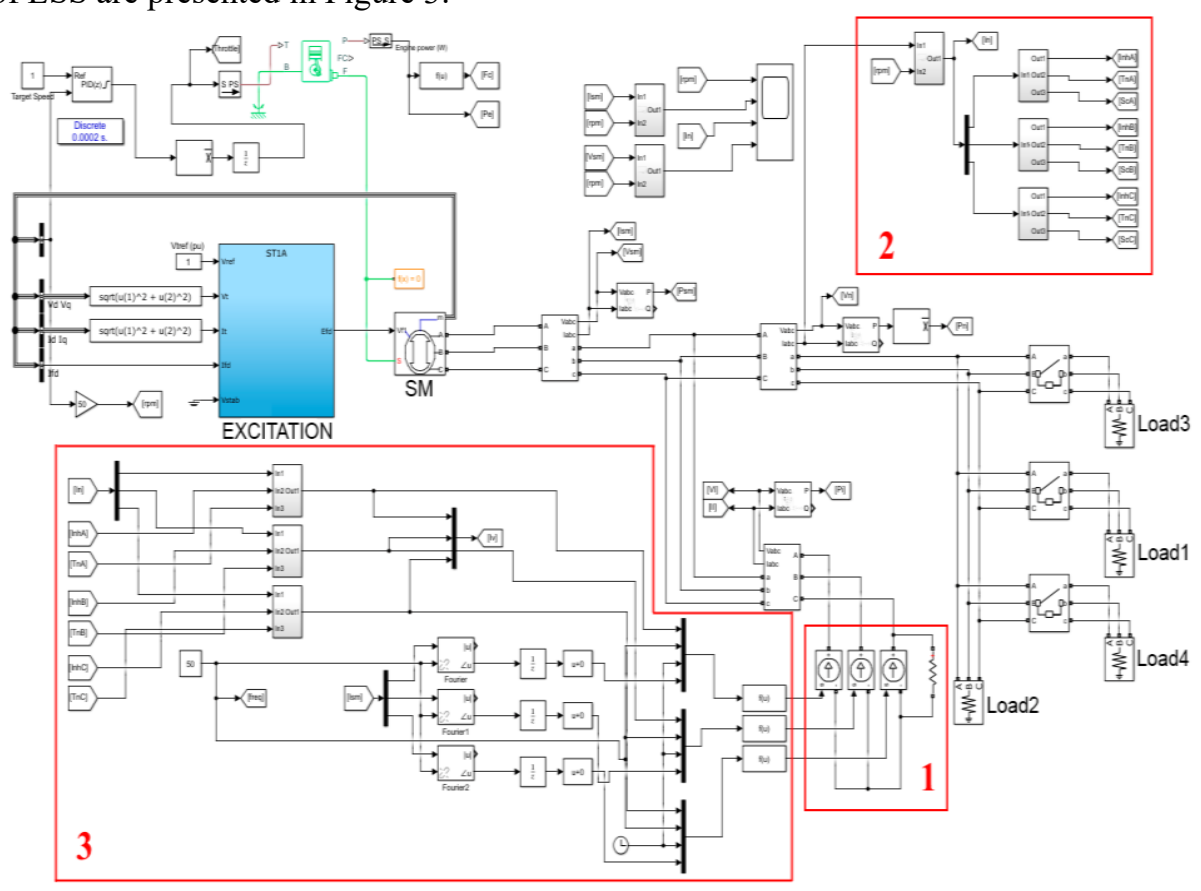

Fig. 2. Simulation model of GPI operation with SG which working in parallel with of alternating current source: 1 - three-phase controlled current source; 2 - a subsystem that captures significant fluctuations in the load current; 3 - subsystem that generates control signals for current sources. 


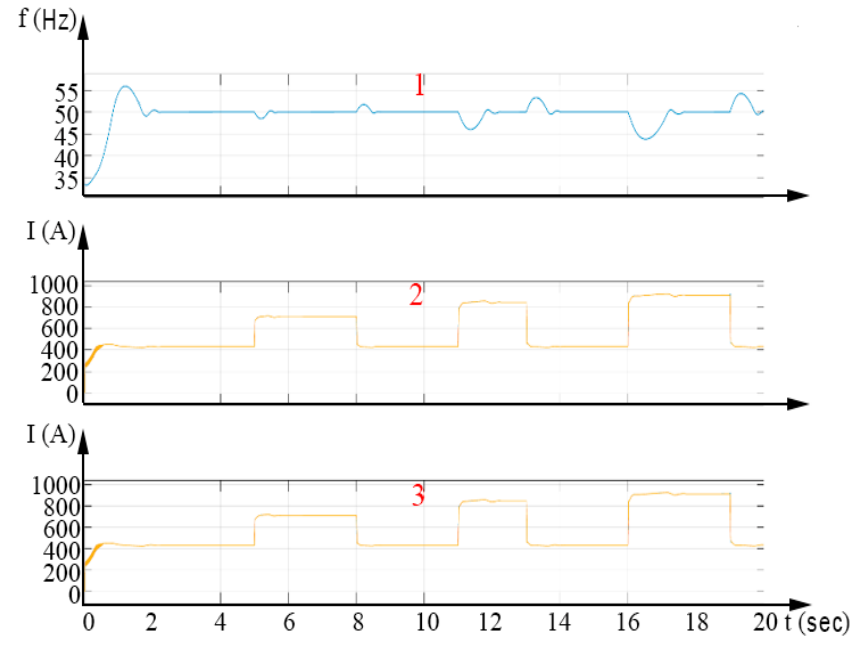

Fig. 3. Measurement of electric grid parameters: 1 - generator voltage frequency, Hz; 2 - the current value of the current SM, A; 3 - the actual value of the load current, A.

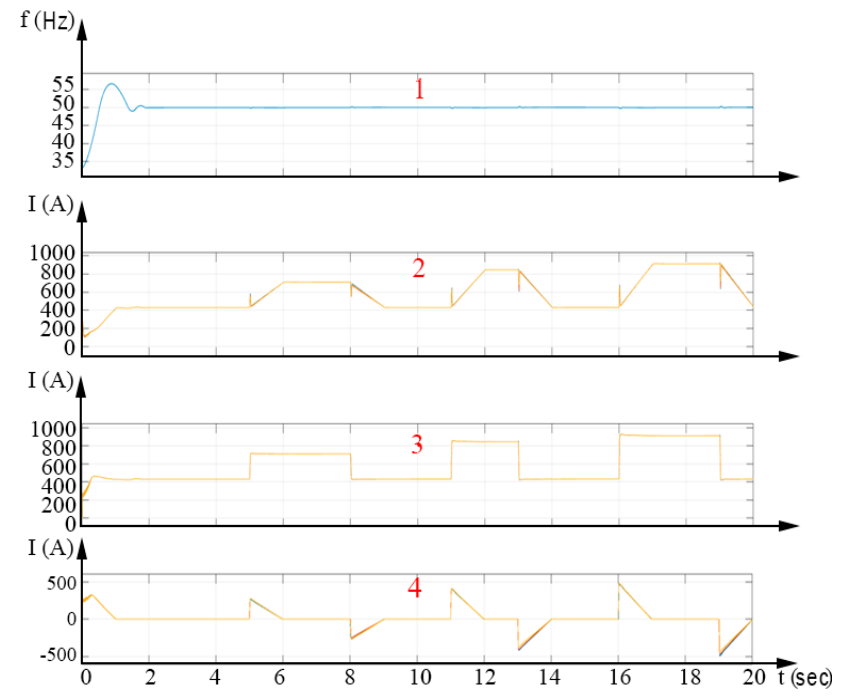

Fig. 4. Changing the parameters of the electric grid in a circuit with a controlled current source: 1 - generator voltage frequency, Hz; 2 - the current value of the current SM, A; 3 the effective value of the load current, A; 4 - the current value of the current source current, A.

\section{Simulation model of industrial power supply system with synchronous machine and energy storage in its composition}

In the schematic diagram, Figure 5, a typical electrical diagram of a centralized industrial power supply is shown, where a three-phase fault occurs on an overhead power transmission line (OPTL) of $110 \mathrm{kV}$ in an external power supply system and provides power to the SM excitation system in the STPO mode from an ESS. The problem is that the applied static valve excitation systems under the influence of STPO become, in fact, self-excitation systems with external faults. Since they are supplied directly from the bus sections of the substation, (transformer T1, Figure 5), due to shortcircuit arises VD because of which the expected result of excitation forcing SM is not achieved, because the rectified voltage on the exciter decreases.

Switching the exciter to ESS (transformer T2 serves only for recharging ESS, Figure 5) allows you to fully use the capabilities of the SM to increase the level of residual voltage. In the case of STPO, voltage recovery in the $10 \mathrm{kV}$ section of the main step-down substation (MSDS) occurs due to the action of Loss of Mains (LoM) protection.

In accordance with the schematic diagram of the power supply of industrial consumers, a simulation model of a typical unit of this system has been developed, 6.

This model allows us to research the effect of excitation forcing SM on the depth of VD caused by a three-phase fault in a $110 \mathrm{kV}$ grid. The simulation model reflects the switching sequence of switching devices in the circuit, Figure 5. At the moment of a three-phase fault, a VD occurs on the tire section. The LoM ensures the launch of a fast-automatic transfer switch (FATS) and gives a command to turn on the excitation forcing SM from ESS [15-17]. In this mode, the power supply system is located until the fault is turned off.

The parameters of the simulation model blocks are described in detail in a previously published work [18].

The initial parameters of the simulated power supply system are as follows.

The distance to the three-phase faults varies from 1 to $30 \mathrm{~km}$, which covers the power supply system of the city and its environs. For the OPTL $110 \mathrm{kV}$, reference characteristics of the steel-aluminum wire AC 120/19 and the intermediate support PS 110-9 V were used. RLC line parameters, which were calculated from the characteristics of the conductor and the support geometry, are automatically entered into the "ThreePhase Pi Section Line" block [14, 19].

A passive load of $8 \mathrm{MW}$ and SEM of $8 \mathrm{MW}$ are connected to $10 \mathrm{kV}$ buses. SEM parameters: $U_{\text {nom }}=10.5$ $\mathrm{kV}, X_{d}=1.41 \mathrm{pu}, X_{q}=0.47 \mathrm{pu}, X_{d}^{\prime}=0.21 \mathrm{pu}, X_{d}^{\prime \prime}=0.101$ $\mathrm{pu}, R_{S}=0.003 \mathrm{pu}[15]$.

Transformer parameters: $S_{\text {nот }}=8 \mathrm{MVA}, U_{l}=110 \mathrm{kV}$, $L_{s(1)}=0,08 \mathrm{pu}, U_{2}=10,5 \mathrm{kV}, L_{s(2)}=0,08 \mathrm{pu}[20]$.

A three-phase short circuit occurs at a time of $0.1 \mathrm{~s}$ on a $110 \mathrm{kV}$ OPTL $17 \mathrm{~km}$ away from industrial consumer buses, Figure 7. The resulting fault causes VD on the buses of the industrial consumer in all 3 phases.

Figure 7 shows the moment of switching on the fourtime field forcing of the SG. As a result, in $20 \mathrm{~ms}$ it is possible to reach a residual voltage level of $80 \%$ of the nominal.

However, due to a rising increase in load on the rotor of the SEM, oscillations appear (Figure 8), which causes a voltage change during the transition process.

Figure 8 shows the waveforms of voltage, phase currents of SEM and the angular velocity of the rotor rotation over a time interval of $5 \mathrm{~s}$. The simulation model does not take into account the energy loss in the rotor and the electrical drive during speed fluctuations. In fact, they fade out quite quickly. The given numerical example shows that due to forcing SM excitation, it is possible to influence the level of residual voltage at the 


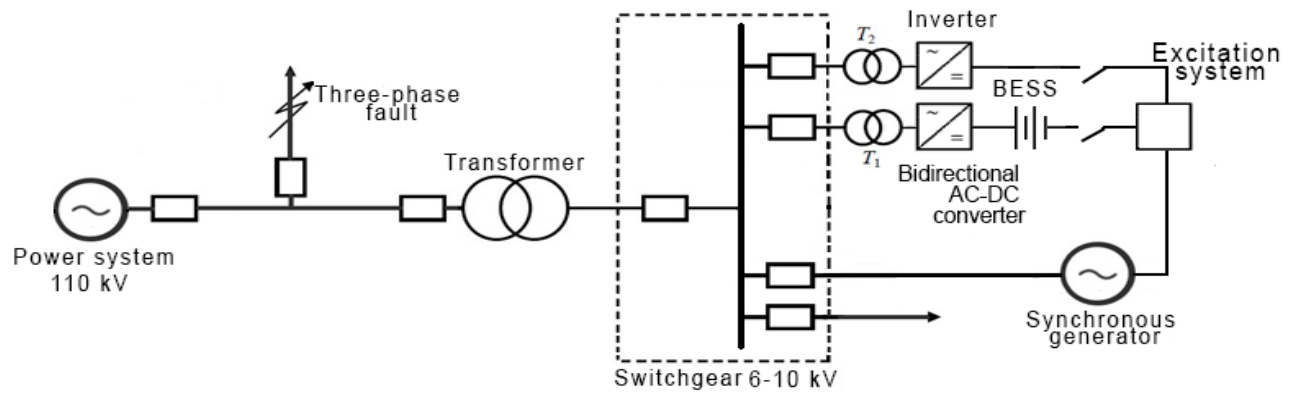

Fig. 5. Schematic diagram of the power supply of an industrial consumer.

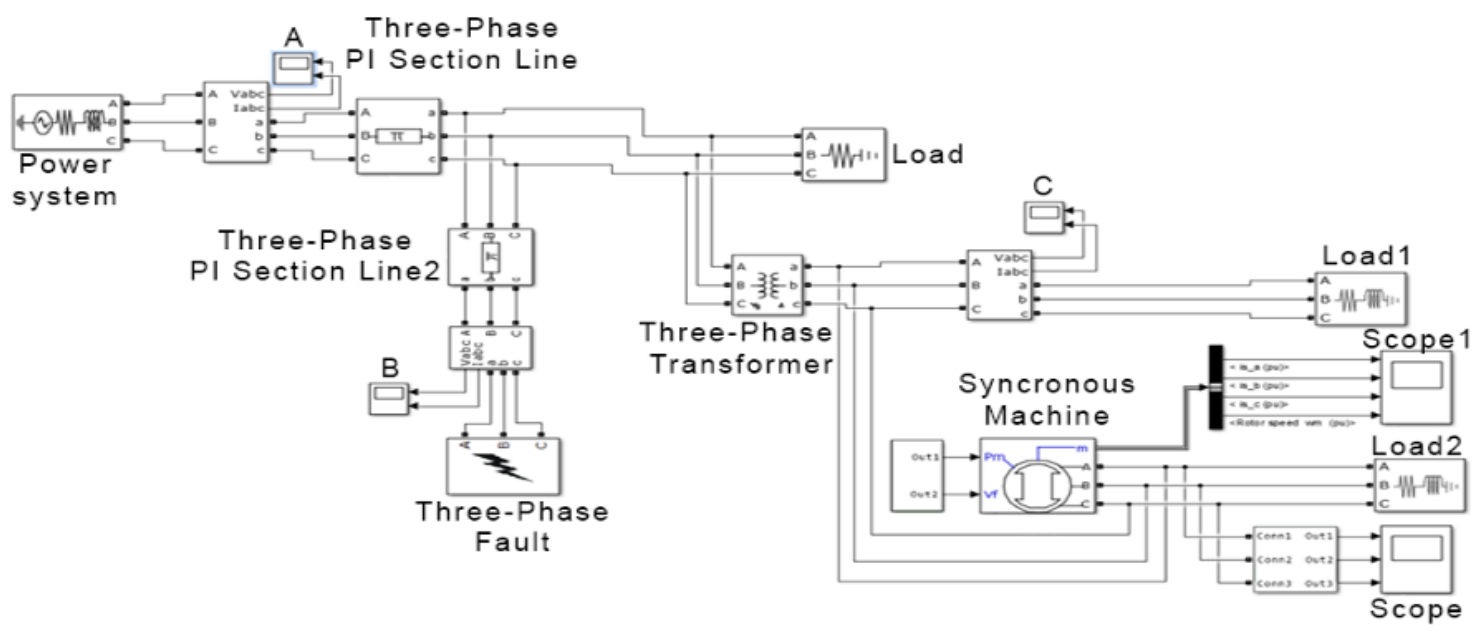

Fig. 6. A simulation model of a typical node of the power supply system of an industrial consumer.

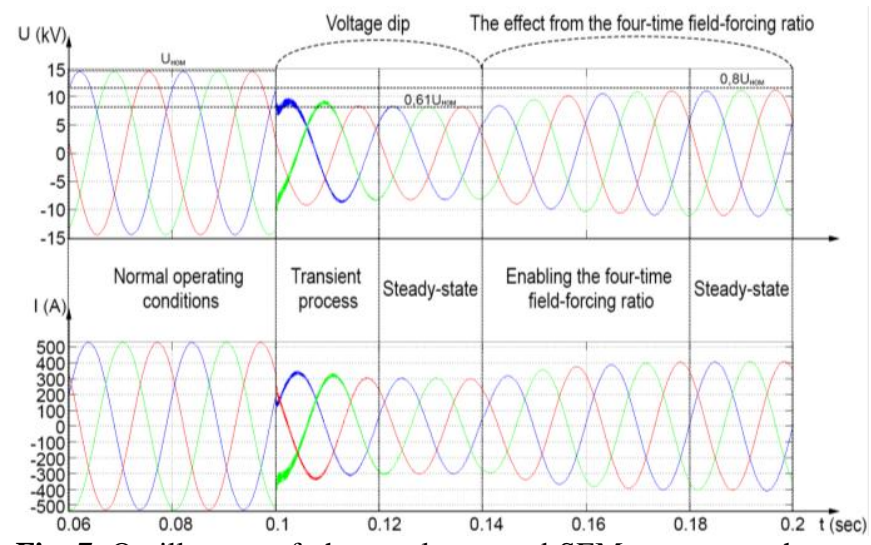

Fig. 7. Oscillogram of phase voltages and SEM currents at the time four-time field forcing.

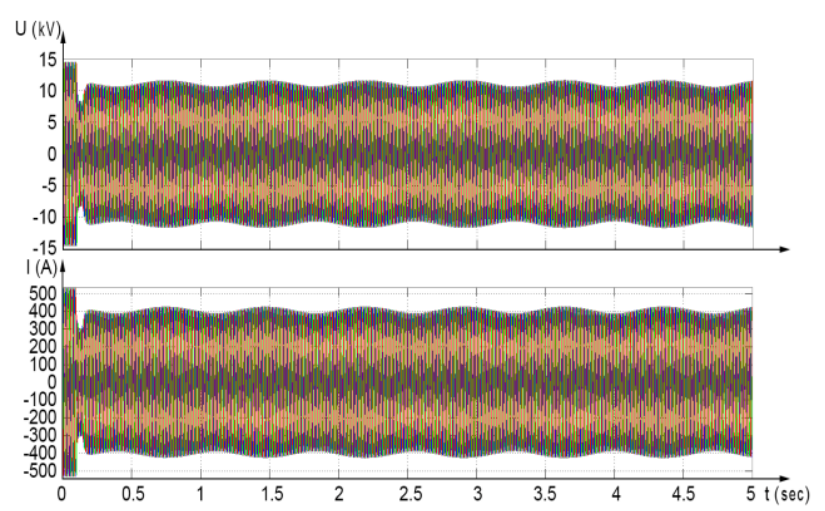

Fig. 8. Oscillogram of operational parameters of SEM. load, and additional costs will be significantly lower than when creating a full-fledged independent power source.

Currently, a small distributed generation is spreading at industrial consumers. To identify the general laws of the influence of the field-forcing ratio of both SG and SEM on the level of residual voltage, a series of model experiments was carried out with different values of the SM power and the length of the OPTL at which a threephase fault occurs. The $\mathrm{c}$ ritical length of the line was used as an efficiency criterion - this is the distance to the location of the short circuit on the OPTL, at which the residual voltage on the load buses is equal to the minimum allowable under the conditions of maintaining its stable working. Obviously, the smaller this value, the smaller the number of STPO affects the work of industrial consumers [21].

The simulation results are presented in Figure 9.

A comparison of the graphs for SEM and SG shows that under the same initial conditions at the level of the specified minimum allowable residual voltage of $80 \%$ of the nominal (taken as an example, depending on motor load; there can be either more or less) the critical length of line for SG less than for SEM a few kilometres. If we compare the efficiency of the field-forcing ratio, then four-time field forcing provides a twofold decrease in the critical length of the OPTL.

Switching exciter to ESS allows you to fully use the capabilities of SM to increase the level of residual voltage. To identify the patterns of influence of the fieldforcing ratio (with independent power supply from the 


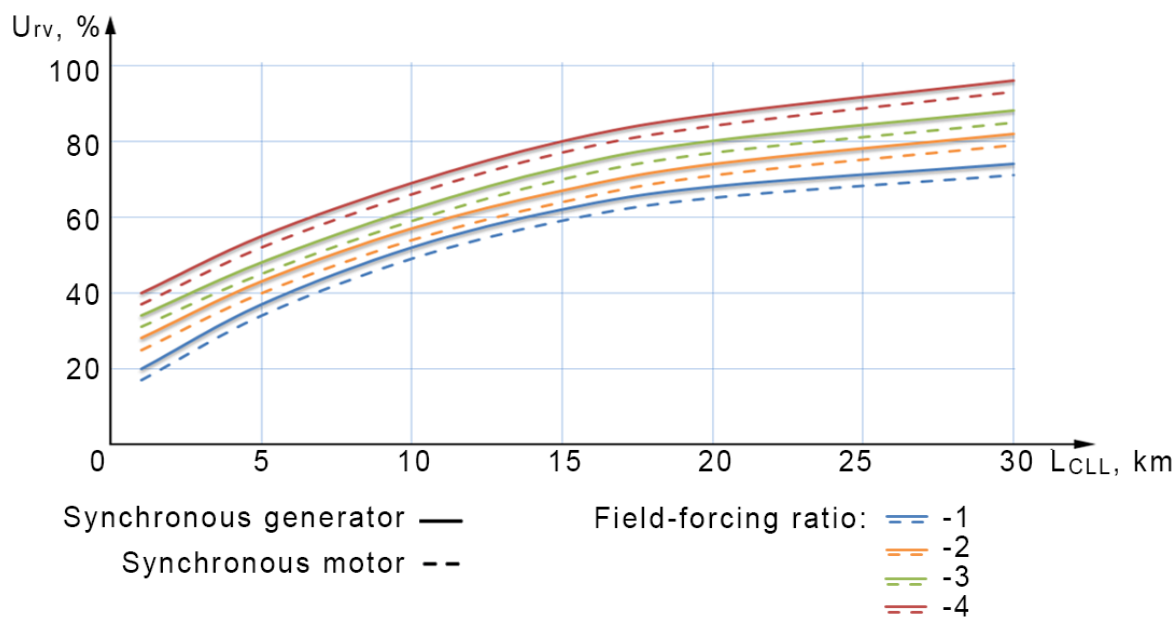

Fig. 9. Identification of the critical length of the line, with the installed rated power of SM 8 MW.

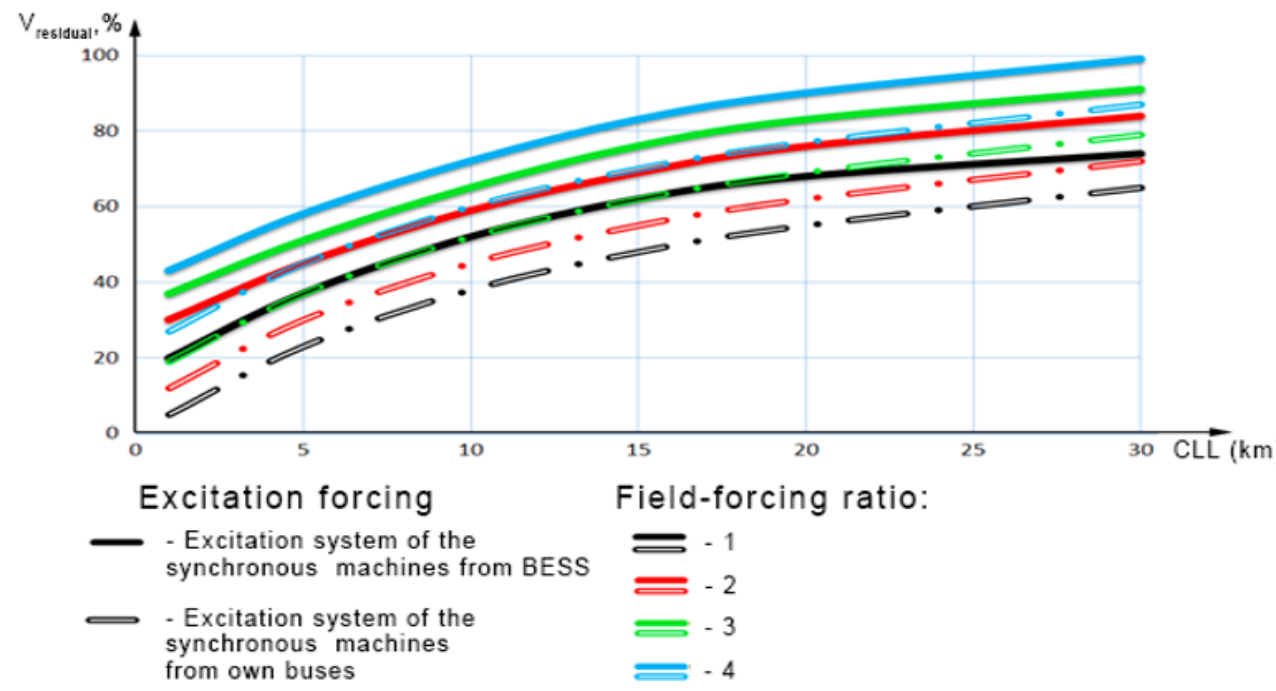

Fig. 10. Comparison of the change in the level of residual voltage.

ESS and the power supply of the exciter from its own buses), a series of experiments were carried out with the SG of $8 \mathrm{MW}$ and the length of the OPTL at which the short circuit occurs. In Figure 10 shows graphs of the dependence of the residual voltage on the magnitude of the critical length of line for SM when supplying their exciter from substation buses (via transformer T1) or from ESS, Figure 5.

Comparison of the graphs for the SG with a system powered by its own buses and an independent excitation system from the ESS shows that at the level of the specified minimum allowable residual voltage of $80 \%$ of the nominal, the critical length of OPTL for the SG with an independent excitation system from the ESS is less than for the SG with the system supplying the exciter from its own buses for 18 kilometers. If we compare the efficiency of the field-forcing ratio the excitation of the SG with an independent excitation system from the ESS, then four-time field forcing provides a twofold reduction in the critical length of the OPTL.

\section{Conclusion}

The use of ESS allows you to limit the depth of the VD. There is an effect of frequency stabilization in an autonomous power supply system with disturbances from the load side in the case of using an ESS as a regulator included in the complex with GPI which work on associated gas. This indicates economic efficiency. The introduction of ESS will contribute to the differentiation of power supply schemes and a general increase in energy efficiency.

The excitation forcing of SM installed in the internal power supply system of industrial enterprises makes it possible to increase the level of residual voltage during VD caused by a three-phase fault in $110 \mathrm{kV}$ supply grids. The increased field-forcing ratio of the SM contributes to a decrease in the critical length of OPTL and, as a result, leads to a decrease in the number of process shutdowns at enterprises with a continuous production cycle. When choosing high-voltage current-limiting protectors designed to increase the level of residual voltage at the MSDS with a three-phase fault in $110 \mathrm{kV}$ supply grids, it is necessary to take into account the capabilities of excitation forcing of SM.

Field-forcing ratio of $\mathrm{SG}$ with an independent excitation system from the ESS, then four-time field forcing provides a twofold reduction in the critical length of the OPTL. When planning the power supply system, it is possible to recommend the placement of several SM (with an increased field-forcing ratio) with a uniform 
load on the section of the MSDS, from which responsible consumers are powered. This will significantly reduce the depth of the VD with close damage in the distribution grid of $110 \mathrm{kV}$.

Research is made with financial support of the Ministry of Education and Science of the Russian Federation within implementation of the federal special program «Research and development in the priority directions of scientific and technological complex of Russia for 2014-2020», the agreement on granting a subsidy № 075-15-2019-057, unique identifier of applied scientific research (project) RFMEFI57418X0188. All research articles should have a funding acknowledgment statement included.

\section{References}

1. K. Bakhteev, A. Fedotov, R. Misbakhov, The improving efficiency of electric receivers on the industrial enterprises in case of short-term power outages, Proceedings of the 2019 20th International Scientific Conference on Electric Power Engineering (EPE), 347-352 (2019)

2. A.E. Veselov, A.S. Karpov, V.V. Yaroshevich, G.P. Fastiy, E.A. Tokareva, Development of a new structure for electricity distribution networks of 6 and $10 \mathrm{kV}$ industrial power supply systems, Vestnik of Kolskogo center of the Russian Academy of Sciences, 4 (2015)

3. A. Fedotov, E. Fedotov, K. Bakhteev, Application of Local Fourier Transform to Mathematical Simulation of Synchronous Machines with Valve Excitation Systems, Latvian Journal of Physics and Technical Sciences, 54 (1) 31-40 (2017)

4. A. V. Belyaev, Emergency control at load nodes with high power synchronous motors, Energetik 88 (2005)

5. A. Fedotov, R. Misbakhov, K. Bakhteev, N. Chernova, Use of electrochemical storages for small generation systems Proceedings - UralCon 2019 40-44 (2019)

6. A.I. Valeev, G.N. Marchenko, Ensuring high reliability of power supply to industrial consumers Energy of Tatarstan, 2 45-51 (2009)

7. S.R. Ildiryakov, Sh.I. Wafin, Statistical analysis of voltage failures in electricity supply system of Kazanorgsintez PJSC, Proceedings of the higher educational institutions. Energy sector problems, 34 73-81 (2011)

8. O Abramova Supercapacitor and Battery Comparison, URL: https://bestenergy.com.ua/support/battery/bu-209 (2016)
9. R.N. Berdnikov, V.E. Fortov, E.E. Son, K.K. Denshchikov, A.Z. Zhuk, N.L. Novikov, Yu.G. Shakaryan, Hybrid electricity storage for the UNEG on the basis of batteries and supercapacitors Energy of the Unified Network, 1 (2013)

10. A. Kuruvita, Optimization of energy storage in electrical networks, Ph.D. thesis 129 (2003)

11. P. Lombardi, B. Arendarski, K. Suslov, N. Shamarova, P. Sokolnikova, A. Pantaleo, P. Komarnicki, A Net-Zero Energy System Solution for Russian Rural Communities, E3S Web of Conferences, 69 (2018)

12. D.N. Cheremnykh, E.V. Tashlykova, M.G. Razepina, Gas-piston plants as an alternative way to generate electricity, Young Scientist, 21 245-247 (2014)

13. Yu. N. Bulatov, A technique for coordinated tuning of automatic regulators of excitation and speed of generators of power plants, Ph.D. dissertation in Engineering Science, 163 (2012)

14. MATLAB-Simulink,

URL: https://www.mathworks.com/

15. S. I. Gamazin, V. A. Zhukov, S. A. Tsyruk, V. M. Pupin, Microprocessor-based high-speed ATS as a means of improving the reliability of power supply for responsible consumers Problems of Energy, 1112 7-12 (2006)

16. A. V. Belyaev, Emergency automation in load nodes with synchronous electric motors of high power. Part 2, URL: https://www.twirpx.com/file/98009/

17. A. A. Vergutin, Improving the reliability of power supply to industrial enterprises through the use of high-speed backup power supply, Scientific and Technical Bulletin of the Bryansk State, 2 (2017)

18. A. Fedotov, R. Misbakhov, E. Fedotov, K. Bakhteev, Influence of voltage dips on the stability of excitation of synchronous machines, Proceedings of the 2019 20th International Scientific Conference on Electric Power Engineering (EPE), 330-335 (2019)

19. D. L. Faybisovich, Handbook for the design of electrical networks, 4th ed., ENAS, 376 (2012)

20. I.P. Kryuchkov, B.N. Neklepaev, V. A. Starshinov, Calculation of short circuits and selection of electrical equipment 416 (2008)

21. K. Bakhteev, A. Fedotov, N. Chernova, R. Misbakhov, Methodological approaches to the choice of energy storage and optimization of their parameters to improve the electric power quality in various types of electric power systems, Proceedings of the 10th International Scientific Symposium on Electrical Power Engineering, Elektroenergetika 488-493 (2019) 